\title{
We Got to Move it, Move it: The Lived Experiences of Family Carers of Youth with Chronic Neurodevelopmental Disorders as They Enter into Adult Health Care
}

\author{
Michelle G. Sy, MD ', \\ Maria Minerva P. Calimag, MD, PhD 2, \\ Rosalina Q. de Sagun, MD 1, \\ Maria Antonia Aurora M. Valencia, MD ${ }^{1}$
}

\section{ABSTRACT}

Background and objective Neurodevelopmental disabilities in adolescents have significant effects on medical and social function. One of these challenges is their transition into adult care. Parental involvement is critical because these young adults may have more difficulties in making informed decisions independently. Thus, the transition process involves not only the direct health care needs of the young adult, but the needs and concerns of the parents or carers who are instrumental in guiding that process. This study aims to explore the expectations and experiences of family carers of youths with chronic neurodevelopmental disorders who have undergone or are about to undergo transition into adult healthcare in a Filipino-based health care system.

Michelle Sy

michgsymd@outlook.com

Section of Child Neurology and Neurodevelopmental Medicine, Department of Pediatrics, University of Santo Tomas Hospital

2 Faculty of Medicine and Surgery, University of Santo Tomas
Methods A descriptive phenomenology was used to gain an in-depth understanding of parents' perceptions and experiences of their youths' transition process from a pediatric to an adult health care setting. The results were analyzed manually using Colaizzi's method, which involves integrating both the destructured and restructured analysis principles of phenomenology. Purposive sampling was used to interview 13 family carers of 13 youths with various neurodevelopmental disorders using a semi-structured interview questionnaire.

Results Despite the lack of information on the transition process, our study found that carers did not have a strong inclination to resist the transition event. Most of the carers treat the health care provider as a major decision maker in determining the timing and manner of transition, adopting a "doctor knows best" attitude. Several other hindrances and facilitators to successful transition were also identified and are similar to the current literature.

Conclusion This study provides a greater understanding of carers' perceptions and experiences of transition care for youths with neurodevelopmental disorders in the local setting. They exhibited trust and 
confidence in the medical profession as a whole, and had a "doctor knows best" antitude that may enable successful transitioning.

Keywords: Phenomenology, lived experiences, transition care, neurology, neurodevelopmental disorders, carers, caregiver experience

\section{INTRODUCTION AND SIGNIFICANCE}

Chronic neurodevelopmental disorders in children have significant effects on adult medical and social function. Impaired level of maturity, adaptability and cognitive function are common problems faced by family carers and health care professionals in the successful transfer in this set of individuals. $[1,2]$ Transitional care is a complex process in which adolescents gradually prepare for and shift toward care from the pediatric into the adult system until formal transfer of care occurs. Identifying an appropriate framework for understanding transition among youths with neurodevelopmental disabilities is important because of the increasing number moving into adulthood. Different models of transition for chronic neurodevelopmental disorders are being used in several countries depending on the varying needs and resources available.[2-5]

Current policy statements may describe the key transition principles such as assuming responsibility for care, enhancing autonomy, personal responsibility and self-reliance.[6-8] Majority of studies examining transition care for young adults with special health care needs focus on physical disabilities. [9] While these studies provide insight into how young adults with chronic conditions and their families prepare for transition, significant differences may exist when the young adult has a neurodevelopmental disability, with or without physical disabilities.[10-12]

Neurodevelopmental disabilities in adolescents have significant effects on medical and social function. One of these challenges is their transition into adult care. Challenges are likely to be greater among youth with neurodevelopmental disabilities because of the complexity of their health care needs. This population is unique in that many young adults have significant intellectual impairments and require significant guidance and reliance from their parents for decision-making and this is unlikely to diminish over time. $[13,14,8]$ It is recognized that those with neurodevel- opmental and cognitive disabilities will continue to be dependent on their families and caregivers throughout adulthood. By and large, the literature surrounding this aspect of healthcare has been composed of studies primarily based in North America, Europe and Australia. [1,2,5,15-18] Of those focused on neurodevelopmental disabilities, recommendations made based on these studies to guide future research and programs were made on the context of their local or national health care system. $[4,14,19,20]$

In the Philippines, professional organizations have yet to produce a consensus statement to address the issue on transition health care. There is a lack of local research and facilities to tackle the growing necessity of organized transitional health care, especially for youths with neurodevelopmental disabilities on the verge of requiring adult medical services.

Parental involvement is critical because these young adults may have more difficulties in making informed decisions independently. Thus, the transition process involves not only the direct health care needs of the young adult, but the needs and concerns of the parents or carers who are instrumental in guiding that process. [13,21-25]

Few studies have acknowledged family involvement in the transition process when a young adult has neurodevelopmental disabilities. Parental perceptions and experiences remain relatively unexplored. Because many of these young adults cannot advocate for themselves, it is essential that we understand the challenges their parents are facing from their own perspective. [19,24,25]

With the aim of helping to fill the gap and paucity in research into the issue, this study aims to explore the expectations and experiences of family carers of youths with chronic neurodevelopmental disorders who have undergone or are about to undergo transition into adult healthcare in a Filipino-based health care system.

\section{METHODOLOGY}

\section{Research Design}

A qualitative aspect was used to explore, uncover and understand each participant's personal and subjective experiences and perspectives of transitioning youths with chronic neurodevelopmental disabilities, in order to capture the richness and complexity of their experiences.[26,27] A descriptive phenomenology was used mainly because of a lack of understanding 
and previous research with respect to the phenomena of transitional care of youths with chronic neurodevelopmental conditions in the Philippine setting.

\section{Study Population}

Information for this research came from carers of youths with chronic neurodevelopmental disabilities who are near, or in the final stage of transitional care - transfer to adult care specialists. All participants are carers of patients of the University of Santo Tomas Hospital Adult Neurology or Pediatric Neurology Ambulatory Care services. Convenience sampling technique was used to select the participants who are in the process of transitioning from pediatric care specialists to adult care specialists.

The investigator used maximum variation sampling, a specific subtype of purposive sampling wherein selected eligible participants are included from a variation of characteristics which may affect the phenomenon of interest according to the established inclusion and exclusion criteria while considering break-and-control characteristics such as age, sex, marital status (ie, single parent, etc.), and employment status (eg, employed or not, etc.).

\section{Data Collection, Instrument and Procedure}

The sample included 13 family carers. Each participant was contacted through messaging, phone call or during consult. All participants were verbally informed by the investigator of the purpose and conduct of the study. Interested individuals agreed to a scheduled interview in a mutually agreed upon time and place by both parties.

All interviews were conducted in person. They were asked to sign a hard copy of the consent form prior to beginning the formal interview process. All participants were provided with, and had signed consent forms either in English, Filipino or both, as per the participant's preference. These were verbally read and clarified to them as needed.

Semi-structured, face-to-face interviews were conducted utilizing a predetermined question guide generated based on the work of Davies, $H$, et al.[19], and on previous informal interviews conducted by the investigators (Table 1).

Participants were encouraged to talk freely and answer using their own words. Interviews lasted 20-40 minutes each. All interviews were conducted by the main investigator. At the end of each interview, the participants were reminded of the need for a second contact via telephone calls to discuss the study findings and to make sure that the study findings reflect their own experiences.

Interviews were recorded through the audio recorder of the investigator's smartphone. Field notes were written at the completion of each interview. Recordings were immediately transferred to a password protected storage device, deleted from phone

Table 1. Guide questions for semi-structured interview

1. Have you ever thought about the eventual transfer of your child from pediatric health care providers to adult health care providers prior to it occurring?

2. What are your main concerns regarding your child's health as $s /$ he moves into adulthood?

3. Have you had discussions with your pediatric health care provider/s about your transfer to adult health care provider/s? What did you feel about those discussions?

What did you feel about each information received?

Are there any other information you would have liked to receive or ask?

4. What are your expectations or experiences regarding the transfer from pediatric health care provider/s to adult health care provider/s?

What difficulties do you anticipate or had experienced?

What advantages do you anticipate or have experienced?

Can you give examples of negative and positive experiences?

Do you have any concerns about the transfer or impending transfer?

5. Were you ready for the transfer from pediatric to adult health care?

6. Do you have any suggestions for improving the process of transfer from pediatric healthcare providers to adult healthcare providers?

7. Do you have any preferences regarding the adult care provider?

Probing questions that can be used at any point during the interview.

"Tell me more about ..."

"Give me examples of ..."

"Explain further this concept you have just mentioned." 
memory and transcribed verbatim by the researcher. Soft copies of the transcriptions were kept in the storage device as well. Each recording and corresponding transcription was labeled with the same numeric code. The transcripts were re-checked by the co-investigator and a third investigator, who has experience in qualitative research.

Data saturation seemed apparent at interview number nine. However, four additional participants made contact and were included in the study. Saturation occurs when ongoing analysis of data from new participants added to the database reveals that no new information or new categories of meaning emerge. There is no specification for an appropriate sample size of a phenomenological study. However, the sample should provide sufficient amount of cases for the development of meaningful points between the participants.

\section{Ethical Considerations}

The study protocol was approved by the Institutional Review Board of the University of Santo Tomas Hospital. All study participants gave written informed consent. Researchers had no access to hospital charts and all participants were assured of confidentiality and anonymity.

\section{Data Analysis}

The analysis for descriptive phenomenological research is a cyclical process. This is an inductive process wherein the goal is to achieve an understanding of the patterns of meanings gleaned from data of lived experiences. Throughout the analysis, the investigator moved back and forth between each step, searching for patterns, exploring for meanings, and determining how such patterns can be organized into themes. The aim is to try to understand the complexity of meanings in the data rather than measure their frequency. An emphasis on open-mindedness and a reflective attitude was adapted throughout the analysis. The results were analyzed manually using Colaizzi's method, which involves integrating both the destructured and restructured analysis principles of phenomenology.[27-30]

\section{Evidence of Trustworthiness}

Central to establishing trustworthiness are the concepts defined by Lincoln and Guba, which involve the criteria of credibility, transferability, dependability and confirmability to provide rigor and strength to the study validity and reliability in all stages including data collection, data analysis and descriptions. [31-33]

Credibility refers to internal validity of quantitative research and was enhanced through the processes of peer debriefing and investigator triangulation with two other members of the research team. Member checking through follow-up phone interview: Of the 13 respondents, 4 were unable to respond to individual member checks since the contact information they provided were not accessible. Preliminary interpretations were then presented to the respondents in a group setting during an institutional lay forum to see if the findings corroborated among the respondents. Of the 13 respondents, 5 were in attendance in this group setting. Persistent observation during the development of concepts and the core categories helped to examine the characteristics of data. Information gathered was constantly read and reread, analyzed, theorized, and revised accordingly through mentoring by an investigator with expertise in qualitative research.

Transferability refers to external validity in quantitative research and it was facilitated through the use of purposive sampling and inclusion of extensive quotations in the analysis.

Dependability refers to reliability and confirmability refers to objectivity. To ensure dependability and confirmability, an audit trail was provided for the research process to be logical, traceable and clearly documented. An investigator who was not involved in the analytical process reviewed the audit trail to determine whether the decision trail can be clearly followed. This is to show evidence whether there was a clear rationale for such decisions and choices made regarding theoretical and methodological issues throughout the study.

\section{RESULTS}

For the numerical data, descriptive statistics in percentage was computed and shown in appropriate tables (Table 2, Table 3 and Table 4).

Three themes were identified

\section{Transitioning is moving out of comfort zone.}

Carers needed to accept transition as a requirement because of the youth's age.

2. Transitioning is moving up to age-appropriate care. 
Table 2. Carers' demographic information

\begin{tabular}{|c|c|c|}
\hline Age & $n=13$ & $\%$ \\
\hline $40-49$ & 6 & $46 \%$ \\
\hline $50-59$ & 3 & $23 \%$ \\
\hline$>60$ & 4 & $31 \%$ \\
\hline \multicolumn{3}{|l|}{ Gender } \\
\hline Male & 2 & $15 \%$ \\
\hline Female & 11 & $85 \%$ \\
\hline \multicolumn{3}{|l|}{ Respondent relation to child } \\
\hline Mother & 9 & $69 \%$ \\
\hline Father & 1 & $8 \%$ \\
\hline Grandparent & 2 & $15 \%$ \\
\hline Other blood relation & 1 & $8 \%$ \\
\hline \multicolumn{3}{|l|}{ Primary residence } \\
\hline NCR & 11 & $85 \%$ \\
\hline Others & 2 & $15 \%$ \\
\hline \multicolumn{3}{|c|}{ Highest educational attainment of respondent } \\
\hline Grade school diploma & 2 & $15 \%$ \\
\hline High school diploma & 1 & $8 \%$ \\
\hline High school undergraduate & 2 & $15 \%$ \\
\hline Vocational/technical & 1 & $8 \%$ \\
\hline College & 7 & $54 \%$ \\
\hline \multicolumn{3}{|l|}{ Medical Financial Assistance } \\
\hline None/Out-of-pocket & 9 & $69 \%$ \\
\hline Relatives & 5 & $38 \%$ \\
\hline Government organization & 3 & $23 \%$ \\
\hline
\end{tabular}

Carers felt eager and willing to transition the youth into adult care as a step up from pediatric care.

3. Transitioning is moving forward into the future.

Carers felt transitioning youths to adult care is a logical next step and a normal process in health care.

\section{Transitioning is moving out of comfort zones}

Carers felt transitioning was something they had to go through despite any reservations or difficulties they experience. They were hesitant of leaving the pediatric care system. Many cited a loss of continuity of care and a loss of familiarity with a system or culture they had grown accustomed to. Parents were anxious in relation to the ability of adult health care services to address their concerns and cited that they
Table 3. Youth demographic information

\begin{tabular}{|c|c|c|}
\hline Age and primary physician & $n=13$ & $\%$ \\
\hline 16-18 years old & 7 & $54 \%$ \\
\hline $\begin{array}{l}\text { Pediatric specialist } \\
\text { Adult specialist } \\
\text { Generalist }\end{array}$ & $\begin{array}{l}7 \\
0 \\
0\end{array}$ & \\
\hline $19-25$ years old & 6 & $46 \%$ \\
\hline $\begin{array}{l}\text { Pediatric specialist } \\
\text { Adult specialist } \\
\text { Generalist }\end{array}$ & $\begin{array}{l}5 \\
1 \\
0\end{array}$ & \\
\hline \multicolumn{3}{|l|}{ Gender } \\
\hline Male & 8 & $61.5 \%$ \\
\hline Female & 5 & $38.5 \%$ \\
\hline \multicolumn{3}{|l|}{ Diagnosis } \\
\hline Seizure disorder & & 10 \\
\hline Cerebral palsy & & 1 \\
\hline Intellectual disability & & 9 \\
\hline Autism spectrum disorder & & 1 \\
\hline $\begin{array}{l}\text { Others } \\
\text { blind } \\
\text { progressive cerebellar ataxia } \\
\text { psychiatric illness } \\
\text { arachnoid cyst } \\
\text { cavernoma } \\
\text { anaplastic astrocytoma }\end{array}$ & & 6 \\
\hline \multicolumn{3}{|l|}{ Day care activity } \\
\hline No day care, stays at home & & 5 \\
\hline Physical therapy & & 1 \\
\hline Occupational therapy & & 0 \\
\hline Speech therapy & & 0 \\
\hline Special education & & 1 \\
\hline Special vocational placement & & 3 \\
\hline Regular school & & 4 \\
\hline
\end{tabular}

would rather remain in pediatric care services if not for the age requiring their transfer.

"Nalulungkot kasi parang nakaka--, kasi kabisado ko na rin dito, biglang malilipat sa neuro ng matanda, hindi ko pa kabisado."

"I'm sad because -, I'm used to it here, then we'll have to suddenly transfer to adult neurology, I'm not yet familiar."

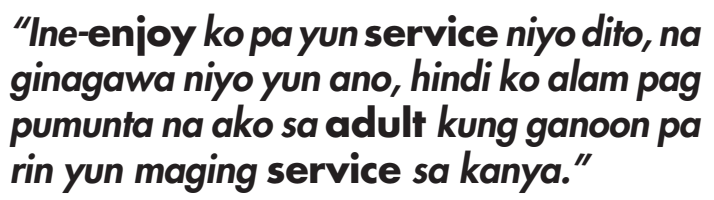
ginagawa niyo yun ano, hindi ko alam pag rin yun maging service sa kanya." 
Table 4. Respondent characteristics

\begin{tabular}{|c|c|c|c|c|c|}
\hline Carer & Age & $\begin{array}{l}\text { Educational } \\
\text { attainment }\end{array}$ & Relation to youth & Illness of youth & $\begin{array}{l}\text { Age of youth / } \\
\text { Have visited adult } \\
\text { care services }\end{array}$ \\
\hline 1 & 63 & $\begin{array}{l}\text { Grade school } \\
\text { diploma }\end{array}$ & Grandmother & Seizure disorder; arachnoid cyst & $17 /$ Yes \\
\hline 2 & 41 & College graduate & Mother & $\begin{array}{l}\text { Progressive cerebellar ataxia; intellec- } \\
\text { tual disability }\end{array}$ & $16 /$ No \\
\hline 3 & 41 & College graduate & Mother & $\begin{array}{l}\text { Cerebral palsy, seizure disorder, intel- } \\
\text { lectual disability }\end{array}$ & $17 /$ No \\
\hline 4 & 60 & $\begin{array}{l}\text { High school } \\
\text { graduate }\end{array}$ & Mother & Seizure disorder & $17 /$ No \\
\hline 5 & 42 & Vocational course & Mother & $\begin{array}{l}\text { Autism spectrum disorder, intellectual } \\
\text { disability }\end{array}$ & $17 /$ Yes \\
\hline 6 & 81 & $\begin{array}{l}\text { High school } \\
\text { undergraduate }\end{array}$ & Grandmother & $\begin{array}{l}\text { Seizure disorder, intellectual disability, } \\
\text { psychiatric illness }\end{array}$ & $21 /$ Yes \\
\hline 7 & 51 & College undergrad & Maternal uncle & Seizure disorder, intellectual disability & $23 /$ Yes \\
\hline 8 & 40 & College undergrad & Mother & $\begin{array}{l}\text { Seizure disorder, anaplastic astro- } \\
\text { cytoma s/p excision, intellectual } \\
\text { disability }\end{array}$ & $21 /$ No \\
\hline 9 & 63 & College graduate & Mother & Seizure disorder, intellectual disability & $19 /$ No \\
\hline 10 & 48 & $\begin{array}{l}\text { Grade school } \\
\text { diploma }\end{array}$ & Mother & Intellectual disability; blindness & $22 /$ Yes \\
\hline 11 & 52 & $\begin{array}{l}\text { High school } \\
\text { undergraduate }\end{array}$ & Mother & Seizure disorder & $17 /$ No \\
\hline 12 & 49 & College undergrad & Father & Seizure disorder, intellectual disability & $17 /$ No \\
\hline 13 & 58 & College graduate & Mother & Seizure disorder, cavernoma & $23 /$ Yes \\
\hline
\end{tabular}

"I enjoy the services you do here. I don't know if it will be the same for him if we go to adult care."

"Sa pedia, eh siyempre doktora, na-ano ko na mas ano sa pedia kasi yun nga ano na trace, yun continuity ng ano, sa ano ng records niya, para sana derederetso lang. Kaya lang yun age nga niya, tumatanda na siya."

"In pediatrics of course, I figured it where it was traced, and continuity in the records, that things will go from there. It's just that he's getting older already."

Carers also hesitate whether it is appropriate for them to transfer. They felt that the pediatric services are better equipped to understand the youth's needs in terms of patience and perseverance in treating neurodevelopmentally challenged youths. They also felt a bond with the doctors who first saw the patient and trusted these individuals to have more knowledge and insight as to the needs of their youth. These carers tend to question the need for transfer and somewhat grudgingly convince themselves that it is the right thing to do based on the doctor's recommendation.

"Kung mas okay na dapat na siya dalhin doon, okay lang sa akin yun, kung mas mabuti yun ganoon dapat siya, na dun na siya dalhin, kung ano yun puwedeng maganda gawin, 0 ano yun dapat na ngang ilagay siya sa adult, why not? Yan nga lang sabi ko nga kung gayon mental capacity niya na 7 years old."

"If he's required to do so, then that is okay with me, if that will be what's best to bring him there. Whichever is good for him, if that means placing him in adult care, why not? It's just that his mental capacity is that of a 7 year old." 
Table. 5 Factors that hindered and facilitated transition

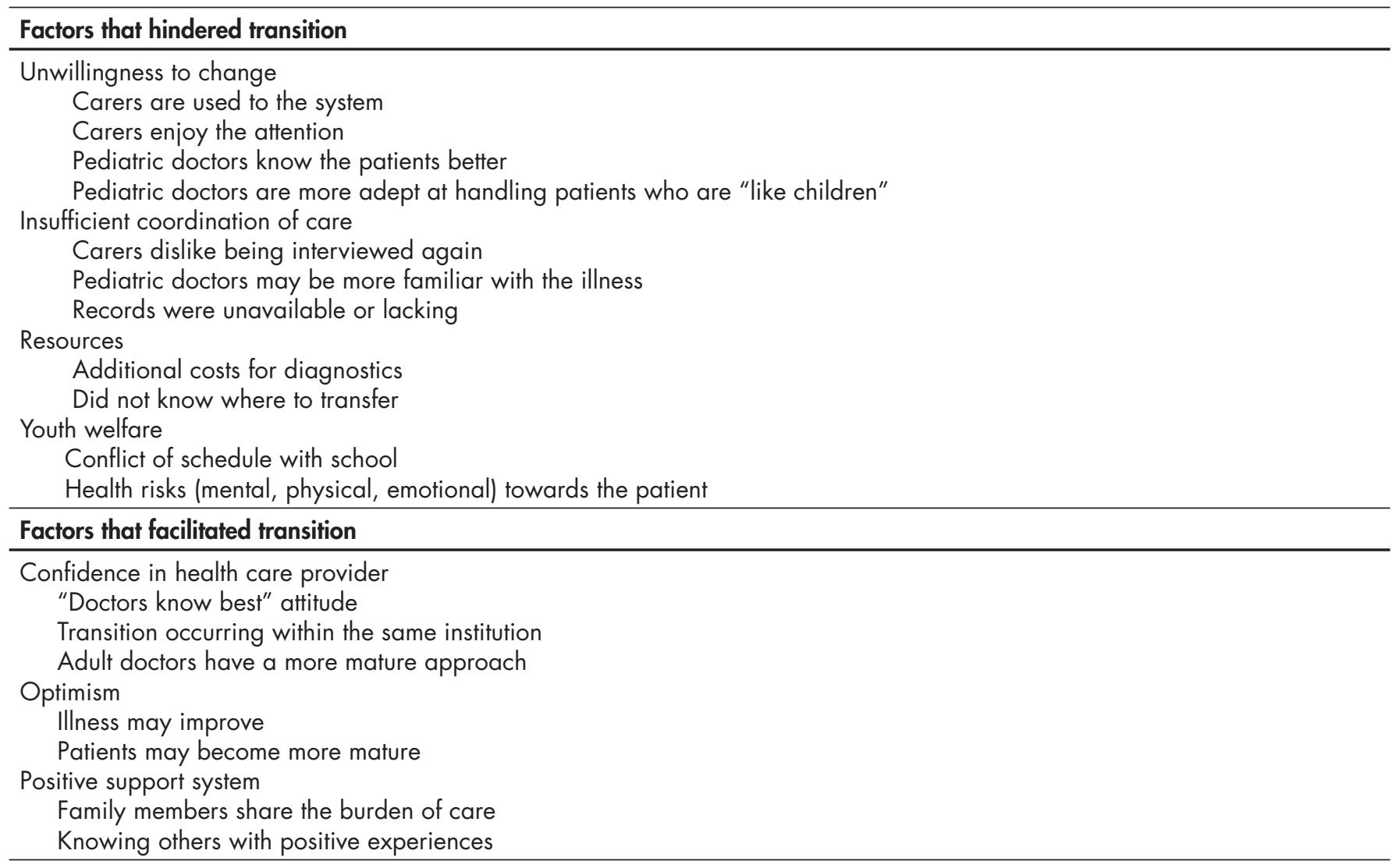

One carer came from a different institution and needed to transfer hospitals. Although the decision to transfer to another institution was made by the mother, she found herself obligated to accept whatever decision was made, despite that she was responsible for accompanying her granddaughter for consults. She explained that they knew they had no choice but to transfer, but at the time, did not know where they will go once her grand-daughter reached 19 years old.

"Ang doktor daw nagsabi na hindi na kayo puwede dito dahil 19 na."; "Hindi rin, kasi nabalitaan ko na sa iba na ganun doon, na aalis at aalis din. Aalis na pala tayo dito na, pag 19 na, doon ko lang naisip na saan nanaman kami pupunta."

and

\section{"Siyempre, nalungkot kami. Malay ko ba saan kung malayo itapon ng nanay niya, mabuti na lang malapit"}

"It was the doctor who supposedly said that we couldn't be there anymore since she is 19 already"; "No, I heard from other people that that is how it is there, that we'll eventually leave. We'll leave when she reaches 19, that's when I started thinking where will we go now?"

and

"Of course we were sad. We didn't know what far off place her mother would send us off to. It's a good thing it [hospital] was just nearby."

Carers identified reasons for preferring to stay with pediatric care, and for worrying about transitioning (Table 5). Carers commonly cited issues with hospital services as a reason for their preference to remain in pediatric care, particularly familiarity with the pediatric care system. They did not look forward to adjusting to a new environment and new people and felt this to be an additional burden. Another concern frequently cited is the lack of coordinated record keeping. One carer experienced that their records were not made available in the adult care service and they were advised to return to the pediatric care to "search" for their records. Many carers suggested the need for proper endorsements of records prior to transfer. They dreaded having to 
repeatedly provide information about their youth's medical history.

Despite citing real and perceived challenges, these carers expressed their willingness to transfer to adult care if that is what their doctor recommends as the best course of action. Although they expressed their preference of staying on with pediatric care, none of the carers completely opposed to transferring.

\section{Transitioning is moving up to age- appropriate care}

Carers view transition not as a loss, but as a process of moving up and a way to help improve the patient. They look forward to transitioning as an opportunity to experience new learnings and as a path towards maturity. Carers felt that a different approach will be beneficial to train the patients to express themselves more, and exposure to less children will help improve the patients' attitude and behavior.

\section{"Yun po kasi pag sa adult na po, parang mas matured po doon eh, kumpara doon sa..."}

and

"Yun sa pagtatanong, pagtatanong po nila. Di ba po puro bata po doon eh, sa pedia. Eh kasi pag doon, iba na yun tanong, mas pang matanda, ganoon po."

"It's just because in the adult care, it seems more matured there, compared with..."

and

"In the questions, in how they ask the questions. Isn't it full of kids, in pediatrics. When we're there, the questions are different, kind of for older people."

One carer related her experience between the cultures of pediatric and adult care when her youth was no longer being "babied" and the consultation focused more on the patient rather than the carer.

"Natuwa naman ako dok, kasi siyempre, maintindihan naman natin na by level naman talaga yun. Kung baga ano, kung ang nahawakan niyo is puro bata, bata lang talaga, tapos yun for adult, adult na din. Okay lang sa akin na yun, ilipat siya sa adult."

"Parang yun approach ng doktor pang adult, hindi yun parang bine-baby pa."

"Siguro dok kasi siyempre adult na siya, iba rin siguro yun training na i-aano sa kaniya, ibibigay."

"I'm happy because we can understand that it's by level. If you handle children, then it's all children, if for adults then for adults. it's okay with me to transfer to adult."

"The approach seem different, they don't "baby" the patient."

"Maybe it's because he's an adult already, the training given will be different."

Another carer wanted to take the initiative to place her son in adult care. She meets with another carer whose youth made the move to adult care and noticed an improvement in the patient. This carer feels that her youth can have a similar experience once they move into adult care services.

\begin{abstract}
"Ang iniisip ko hindi siya ilalagay sa adult, so ako na lang magtatanong sana kung puwede nga siya ilagay sa adult para maiba naman yun pananaw niya sa ano, sa buhay niya, yun ma-iba yun linya ng ginagawa niya sa araw-araw."

"I was thinking she wouldn't be placed in adult services, so I wanted to ask about it myself if she can be transferred there so that she can have a different outlook in life, so that there would be a change in her day-to-day."
\end{abstract}

\section{Transitioning is moving forward into the future}

Carers felt transitioning is a normal procedure and as long as they get seen by doctors within the same institution, there will be little cause for concern. They felt transitioning to adult care services is a logical next step for their youth.

"Oo, kasi di ba mag se-17 na siya, siyempre dapat ang mag ha-handle sa kaniya ay yun sa adult na doktor. Wala naman, okay lang naman po, kasi talagang pagdadaanan naman niya. 


\section{Okay lang naman lumipat, di ba, wala naman problema."}

and

\section{"Wala naman, siguro kasi isang ospital lang naman ito eh."}

\begin{abstract}
"Yes, because he is almost 17 and naturally an adult doctor should handle him. It's not a problem since it's something that has to happen. We don't mind transferring."

and
\end{abstract}

"I don't think there will be [problems], it's the same hospital anyway."

\section{"Kasi hindi naman habang buhay na nandun siya sa pedia."}

"Ok lang kasi parang ganun din ho ang titingin sa kaniya, adult nga lang. Ganun din."

"Because she can't be seen by a pediatrician for her entire life."

and

"It's okay because she'll still get seen, just by an adult specialist. It's all the same."

When asked about their thoughts on transitioning, one carer preferred to stay in the same institution despite living in the province. She maintains that it would not matter whether they were placed in a pediatric or adult care service as long as it will remain in the same institution.

"Sa akin naman po dok, ako naman po talaga doktora, honestly, gusto ko talaga dito sa UST. Matagal ko na inisip yan, kaya lang dahil malayo kami, tama po bang magpalipat na ako ng malapit na hospital doon, tingin mo?"

and

"Yun talaga yun, kaya hindi talaga ako makalipat ng ibang ospital. Ti-nry namin po, inisip namin lahat po kayo dito is talagang magaling."

"For me, I really, honestly want it here in UST. I thought about it for a long time, but because we live so far, is it right if we are transferred to a nearby hospital, what do you think?"

and
"That is why we couldn't switch to a different hospital. We tried but we think you are all really good here."

\section{DISCUSSION}

To date, this is the first study done in the Philippine setting that explored the lived experiences of carers of youths with neurodevelopmental disabilities transitioning to adult care. The purpose of this study was to enhance our understanding of carers' perceptions of the transition process from pediatric to adult health care services when their young adult has a chronic neurodevelopmental condition.

Much has been written about transition being a gradual and purposeful process rather than a static event $[16,34]$, and this has been advocated and successfully implemented in countries such as the United States, Canada and Australia, including disease-specific transition programs for chronic illnesses. Data on transition programs in Asia have been less robust with large gaps in program development. [35-37] There is also a growing number of studies tackling the more complicated process of transitioning youths with various chronic neurodevelopmental disabilities. $[3,8,10,14]$

In the United States, Canada and Australia, healthcare providers are required to formulate a transition care plan shortly after diagnosis and prepare the patient and family before the transition process actually occurs. In these areas, a care coordinator, commonly a clinical nurse specialist coordinates the transition period and bridges the gap between pediatric and adult care services. The Japanese healthcare system utilizes specialized nurses to manage the transition of patients with childhood-onset chronic diseases. This has resulted in a positive pediatric to adult healthcare transition. [38]

Our carers perceived several factors that hindered or facilitated the transition process. Literature supports the importance of understanding the carers' needs during this process, as they are the ones who require preparation.[19] Our study has revealed that carers reported little, if any, knowledge about future care services and hardly asked about the impending needs of their young adult. Timing and amount of disclosure of information were largely left to the discretion of the health care provider. However, carer perception of the transition process is by and large minimized to an inevitable event of 
transferring to adult care services, with only limited discussions about the process in the months preceding the transition.

Despite the lack of information on the transition process, our study found that carers did not have a strong inclination to resist the transition event. Most of them treat the healthcare provider as a major decision-maker in determining the timing and manner of transition, adopting a "doctor knows best" attitude. This approach to decision-making allows less opportunity for individual choice in medical care. This is in stark contrast with the available literature where more carers tend to take a proactive stance in the process of transitioning. $[13,14,39]$ However, most of the transition literature is concentrated on Western cultures that advocate an individualistic health care concept. This may not be true for the Asian collectivist culture that may abdicate decision-making to the physician who is expected to make decisions that are in the best interest of the greatest number of people involved with the patient.[40,41] A study in Hong Kong (35) showed that a majority of parents and adolescents were willing to transfer to adult-oriented services, despite a very small percentage having received any information on the transition process. In this case, they found that the adolescent's perception of his/her own responsibility toward the illness was positively associated with their transition decision, but trust and confidence towards their doctor was found to be non-significant. The implication of culture and regional differences in the success of transition remains to be seen.

With limited discussions and guidance about the transition process, it was generally only at their young adult's last appointment in the pediatric setting that future care was discussed. The prevailing model that promoted transfer rather than a gradual process of preparation may influence carers' perspectives on transition.

Carers were hesitant to transfer to adult neurology care services because of their familiarity to the system and people in the pediatric neurology care services. Some reported higher confidence and trust in the doctors who were responsible for the initial diagnosis and management of their patients, while others reported their resistance to change as they felt that transfer is an added burden of adjusting to a new system and new people. This unwillingness to change is similar to that given in literature. $[19,23,35]$
Many carers were concerned about the insufficient coordination of patient records. They believed that this process would be automatically completed in the pediatric setting, then endorsed to and reviewed by the adult care practitioner by the first visit. Many felt frustrated at the prospect of being repeatedly asked about their youth's medical history considering the chronicity and complexity. They felt that the receiving doctor should already have adequate knowledge about the patient upon their transfer. When the pediatric health care service did provide a referral to the adult health care service, carers found that accompanying documentations were lacking. This was perceived by carers as a lack of coordination between services, placing additional burden on them to recall entire events of a chronic illness with the adult care specialists. This was similar to that given in literature. $[9,13,20]$

None of the participants considered finances a distressing issue. Although, some carers perceive that a transfer to another doctor or service would mean a repetition of previous diagnostic tests they would have to first prepare for financially before transition. This, however appears to have less impact than in other studies where aging out of the pediatric services meant a loss of health insurance. $[17,42]$ The healthcare setting in the institution is largely dependent on out-of-pocket settlement of hospital and doctor's fees. Because of this, the idea of preparing for additional costs is perceived as a norm for any new consultation rather than a sudden loss of benefits from aging out of the system. This is also in contrast with the Taiwanese study [36] on adolescents with cancer, which revealed that a majority of parents place their children in adult-oriented services prematurely. The availability of cheap healthcare access across all age groups and lack of knowledge of pediatric-oriented services were cited as reasons for parents to choose a specialty based on the department concerned (oncology).

This study did not explore the perceptions of the young adult. Carers were concerned about their vulnerability should they be transferred to the adult care services. They perceive their young adults to be in danger of being unprepared to enter the environment and culture of adult care services. They reported anxieties and concerns on the dangers posed to their young adult being unable to handle themselves during the visit to the adult care specialist. This is not surprising, as these youths often have insufficient 
knowledge about their condition, and even the simplest parts of their care have been attended to by the carers. $[43,44]$

It is worthwhile to note that a positive support system and an optimistic outlook seem to improve the carers' perception of the transition process. Similar results on carer resourcefulness were reported. $[21,19,44]$ The availability of others within the family to share responsibilities in caring for the youth facilitated the transition experience of the participant.

Much of the literature focusing on transition in neurodevelopmental illnesses $[2,14]$ indicate unpreparedness of families to move into adult care services. We found that the carers who looked forward to the transition to adult care services reported it as the best course of action in order to facilitate improvement in their youth. They perceived the transfer to adult care as a step-up from child-oriented care and an avenue for their youth to model more mature behaviors and have improved interpersonal relationships at home. This perceived age-appropriate approach of the adult care services was deemed advantageous in young adults with chronic disabilities that were not neurodevelopmental in nature,[39] and interviews on carers with autistics youth in education and vocation transitions mentioned the need of mentors from whom their youth can imitate more mature behaviors. [45] However, this finding was not reported by carers in qualitative studies on healthcare transitions focusing on neurodevelopmental illnesses.[13,19,24,44]

Models of transition have been described $[5,20,46,47]$ and the most appropriate to use depends largely on the resources available. Difficulties in accessing an adult specialist have been reported as a barrier to successful transition. $[19,24,48]$

Our setting of having multiple specialties available within the same institution gave a sense of confidence and security in carers that their youth will be well taken care of. The current transition model moved youths from the pediatric subspecialty service to the adult subspecialty service within the same university hospital and only one carer-participant came from an exclusively pediatric care facility. Because most of the professionals in pediatric and adult care knew each other, transition can occur with informal verbal communication between specialists.
Joint consultations or joint training and educational experiences with both pediatric and adult specialists are deemed effective ways to tie together the transition period and address concerns from patients and families.[18,42,43,46] Adding a joint consultation clinic where both pediatric and adult specialists are available may be feasible to implement in this case and further improve the success of transition. Other studies indicate a single specialized nurse to assist patients and carers in both clinics that also enhanced success in transition. $[37,43]$

\section{CONCLUSION AND IMPLICATIONS FOR PRACTICE}

This study provides a greater understanding of carers perceptions and experiences of transition care for young adults with neurodevelopmental disorders in the local setting. Our study has revealed carers reported little if any knowledge about adult care services and hardly asked about the impending needs of their young adult. They perceived numerous challenges associated with the transition process of the young adult with a chronic neurodevelopmental condition. Carers identified barriers or challenges that were similar to those seen in literature. However, a majority of them exhibited an attitude of "doctors know best" towards transition care regardless of how they felt about transitioning. This was not reported in other studies. The trust and confidence in the medical profession as a whole may enable successful transitioning in the local setting.

\section{LIMITATIONS}

One important message gleaned from this study was a lack of providers' awareness on transition care. Very little information was received from the pediatric care provider during a routine visit. This study did not address the barriers on the providers' side but it indicated that they did not appear well-equipped to fully facilitate the transition process. It would be beneficial if we could understand the practical difficulties of physicians in implementing the transition model. Additionally, with the sample size and study design utilized, the impact of demographic factors or severity of disability on carer experiences cannot 
be determined. The generalizability of this study was also limited by the use of a single non-government university hospital from a single region (National Capital Region), though two participants recruited were from provinces within the same island (Luzon).

\section{Conflict of Interest Statement}

All authors (Drs. Michelle G. Sy, Maria Minerva P. Calimag, Rosalina Q. de Sagun and Maria Antonia Aurora M. Valencia) declare that the research was conducted in the absence of any commercial or financial relationships that could be construed as a potential conflict of interest. 


\section{REFERENCES}

1. Stewart D. Transition to adult services for young people with disabilities: current evidence to guide future research. 2009:51:169-73.

2. Camfield P, Camfield C. Transition to adult care for children with chronic neurological disorders. Annals of Neurology [Internet]. $2011 ; 69(3): 437-44$. Available from: https:// onlinelibrary.wiley.com/doi/abs/10.1002/ana.22393

3. Andrade DM, Bassett AS, Bercovici E, Borlot F, Bui E, Camfield $P$, et al. Epilepsy: Transition from pediatric to adult care. Recommendations of the Ontario epilepsy implementation task force. Epilepsia. 2017;58(9): 1502-17.

4. Epilepsy: addressing the transition from pediatric to adult care. Adolesc Health Med Ther. 2016;77-87.

5. Carrizosa J, An I, Appleton R, Camfield P, Moers A Von. Transition of epilepsy care from children to adults. Models for transition clinics. Transition in Canada. 2014;55:46-51.

6. Patel A. Lost in transition? A practice tool for finding your way to adulthood. Epilepsy Curr. 2013 Jul; 13(4):186-7.

7. Adams RC, Levy SE. Shared Decision-Making and Children With Disabilities: Pathways to Consensus. Pediatrics [Internet]. 2017 May 29;139(6):e20170956. Available from: http://dx.doi.org/10.1542/peds.2017-0956

8. Racine E, Bell E, Yan A, Mdcm GA, Mdcm LEB, Clarke M, et al. Ethics challenges of transition from paediatric to adult health care services for young adults with neurodevelopmental disabilities. 2014;19(2):65-8.

9. Young NL, Barden WS, Mills WA, Burke TA, Law M, Boydell K. Transition to adult-oriented health care: Perspectives of youth and adults with complex physical disabilities. Phys Occup Ther Pediatr. 2009;29(4):345-61.

10. Gauthier-Boudreault C, Gallagher F, Couture M. Research in developmental disabilities specific needs of families of young adults with profound intellectual disability during and after transition to adulthood: What are we missing? Res Dev Disabil. [Internet]. 2017;66(June 2016):16-26. Available from: http://dx.doi.org/10.1016/i.ridd.2017.05.001

11. Magill-evans J, Wiart L, Darrah J, Kratochvil M, Wiart L, Darrah J, et al. Physical \& occupational therapy in pediatrics beginning the transition to adulthood beginning the transition to adulthood: the experiences of six families with youths with cerebral palsy. 2016;2638(March).

12. Crane S, Self A, Network A. Autistic self advocacy network. 2013; (July): 1-12.

13. Heus KGCBB, Staa A Van, Vliet I Van, Ewals FVPM, Hilberink SR. Transferring young people with profound intellectual and multiple disabilities from pediatric to adult medical care: parents' experiences and recommendations. 2013;51(3): 176-89.

14. Brown M, Macarthur J, Higgins A, Chouliara Z. Transitions from child to adult health care for young people with intellectual disabilities: A systematic review. J Adv Nurs. 2019;0-2.

15. Morsa M, Gagnayre R, Deccache C, Lombrail P. Patient education and counseling factors influencing the transition from pediatric to adult care: A scoping review of the literature to conceptualize a relevant education program. 2017;100:1796-806.

16. Gabriel P, McManus M, Rogers K, White P. Outcome Evidence for Structured Pediatric to Adult Health Care Transition Interventions: A Systematic Review. The Journal of Pediatrics [Internet]. 2017 Sep; 188:263-269.e15. Available from: http://dx.doi.org/10.1016/i.jpeds.2017.05.066
17. Wang G, McGrath BB, Watts C. Health Care Transitions Among Youth With Disabilities or Special Health Care Needs: An Ecological Approach. Journal of Pediatric Nursing [Internet]. $2010 \mathrm{Dec} ; 25(6): 505-50$. Available from: http://dx.doi.org/10.1016/i.pedn.2009.07.003

18. Sonneveld $H M$, Strating $M M H$, van Staa $A L$, Nieboer AP. Gaps in transitional care: what are the perceptions of adolescents, parents and providers? Child: Care, Health and Development [Internet]. 2012 Feb 13;39(1):69-80. Available from: http://dx.doi. org/10.1111/j.1365-2214.2011.01354.x

19. Davies BH, Cnn C, Rennick J, Majnemer A. Transition from pediatric to adult health care for young adults with neurological disorders: Parental Perspectives. 2011;33(2).

20. Tuffrey C, Pearce A. Transition from paediatric to adult medical services for young people with chronic neurological problems. J Neurol Neurosurg Psychiatry. 2003 Aug;74(8):1011-3.

21. Mu PF. Transition experience of parents caring of children with epilepsy: A phenomenological study. Int J Nurs Stud. 2008;45(4):543-51.

22. Cabbeh KD, Jerome B, Villafuerte A, Kaye J, Ruiz O, Adanza JR. Lived experiences of parents of children with intellectual disability undergoing pre-vocational education. 2015;3:1-15.

23. Schultz RJ. Parental experiences transitioning their adolescent with epilepsy and cognitive impairments to adult health care. J Pediatr Heal Care [Internet]. 2013;27(5):35966. Available from: http://dx.doi.org/10.1016/i. pedhc. 2012.03 .004

24. Kuhlthau KA, Delahaye J, Erickson-Warfi M. Health care transition services for youth with autism spectrum disorders: Perspectives of caregivers. 2016;137(February).

25. Burkhard A. A different life: caring for an adolescent or young adult with severe cerebral palsy. J Pediatr Nurs [Internet]. 2013;28(4):357-63. Available from: http://dx.doi. org/10.1016/i.pedn.2013.01.001

26. Norlyk A. Qualitative Health Research. 2014;(February).

27. Lopez KA, Willis DG. Qualitative health research descriptive versus interpretive phenomenology: their contributions to nursing knowledge. 2014; (June 2004).

28. Banchetti-Robino MP. Phenomenology of science and the problem of induction. 1995.

29. Morley J. The descriptive phenomenological psychological method. 2017;(July).

30. Groenewald T. A phenomenological research design illustrated. 2004;42-55. Available from: hitps://doi. org/10.1177/160940690400300104

31. Shenton AK. Strategies for ensuring trustworthiness in qualitative research projects strategies for ensuring trustworthiness in qualitative research projects. 2016;(July 2004).

32. Nowell LS, Norris JM, White DE, Moules NJ. Thematic analysis: Striving to meet the trustworthiness criteria. 2017;16:1-13. Available from: https://doi. org/10.1177/1609406917733847

33. Anney VN, Dar POB, Salaam E. Ensuring the quality of the findings of qualitative research: Looking at trustworthiness criteria. 2014;5(2):272-81.

34. Campbell F, Biggs K, Sk A, Pm ON, Clowes M, Mcdonagh $J$, et al. Transition of care for adolescents from paediatric services to adult health services (Review) Summary of findings for the main comparison. 2016;(4).

35. Wong LHL, Chan FWK, Wong FYY, Wong ELY, Huen $\mathrm{KF}$, Yeoh EK, et al. Transition care for adolescents and 
families with chronic illnesses. J Adolesc Heal [Internet]. 2010;47(6):540-6. Available from: http://dx.doi. org/10.1016/i.jadohealth.2010.04.002

36. Jin YT, Chen CM, Chien WC. Factors influencing transitional care from adolescents to young adults with cancer in Taiwan: A population-based study. BMC Pediatr [Internet]. 2016;16(1):1-8. Available from: http://dx.doi. org/10.1186/s12887-016-0657-z

37. Ishizaki $Y$, Maru M, Higashino H, Katsumoto S, Egawa K, Yanagimoto $Y$, et al. The transition of adult patients with childhood-onset chronic diseases from pediatric to adult healthcare systems: A survey of the perceptions of Japanese pediatricians and child health nurses. Biopsychosoc Med [Internet]. 2012;6(1):8. Available from: http://www. bpsmedicine.com/content/6/1/8

38. Ishizaki $Y$, Higashino $H$, Kaneko K. Promotion of the transition of adult patients with childhood-onset chronic diseases among pediatricians in Japan. Front Pediatr. 2016;4(Oct): 1-5.

39. vanStaa AL, Jedeloo S, van Meeteren J, Latour JM. Crossing the transition chasm: Experiences and recommendations for improving transitional care of young adults, parents and providers. Child Care Health Dev. $2011 ; 37(6): 821-32$.

40. McLaughlin LA, Braun KL. Asian and Pacific islander cultural values: Considerations for health care decision making. Heal Soc Work. 1998;23(2): 116-26.

41. Weijer C. Bioethics: An anthology. BM. 2000;320(7243): 1215.

42. Reiss JG, Gibson RW, Walker LR. Health Care Transition: Youth, Family, and Provider Perspectives. Pediatrics [Internet]. 2005 Jan;1 15(1):112-20. Available from: http:// dx.doi.org/10.1542/peds.2004-1321

43. Camfield P, Camfield C, Pohlmann-Eden B. Transition from pediatric to adult epilepsy care: A difficult process marked by medical and social crisis. Epilepsy Curr. 2012;12(4_suppl):13-21.
44. Franklin MS, Beyer LN, Brotkin SM, Maslow GR, Pollock $M D$, Docherty SL. Health care transition for adolescent and young adults with intellectual disability: Views from the parents. J Pediatr Nurs. 2019;47:148-58.

45. Cheak-Zamora NC, Teti M, First J. "Transitions are Scary for our Kids, and They're Scary for us": Family member and youth perspectives on the challenges of transitioning to adulthood with autism. J Appl Res Intellect Disabil. $2015 ; 28(6): 548-60$.

46. lyer A, Rajendran S. Epilepsy: addressing the transition from pediatric to adult care. Adolesc Health Med Ther. 2016; 7:77-87.

47. Camfield PR, Gibson PA, Douglass LM. Strategies for transitioning to adult care for youth with Lennox-Gastaut syndrome and related disorders. Epilepsia. 201 1;52(Suppl. 5):21-7.

48. Gorter JW. Transition to adult-oriented health care: Perspectives of youth and adults with complex physical disabilities. 2009;29(4):362-7.

(i) Open Access This article is licensed under a Creative Commons Attribution 4.0 International License, which permits use, sharing, adaptation, distribution and reproduction in any medium or format, as long as you give appropriate credit to the original author(s) and the source, provide a link to the Creative Commons license, and indicate if changes were made. The images or other third party material in this article are included in the article's Creative Commons license, unless indicated otherwise in a credit line to the material. If material is not included in the article's Creative Commons license and your intended use is not permitted by statutory regulation or exceeds the permitted use, you will need to obtain permission directly from the copyright holder. To view a copy of this license, visit http://creativecommons.org/licenses/by/4.0/. 